\section{Public Health Genomics}

Public Health Genomics 2016;19:307-313

DOI: $10.1159 / 000448913$
Received: January 11, 2016

Accepted: August 6, 2016

Published online: September 8, 2016

\title{
Let the Individuals Directly Concerned Decide: A Solution to Tragic Choices in Genetic Risk Information
}

\author{
Serena Oliveri ${ }^{a, b}$ Gabriella Pravettoni ${ }^{a}{ }^{b}$ Chiara Fioretti ${ }^{b} \quad$ Mats G. Hansson ${ }^{c}$ \\ anterdisciplinary Research Center on Decision Making Processes IRIDe, Department of Oncology and Hematology, \\ University of Milan, and ${ }^{\mathrm{b}}$ Applied Research Unit for Cognitive and Psychological Science, IEO Istituto Europeo di \\ Oncologia, Milan, Italy; ${ }^{\complement}$ Centre for Research Ethics and Bioethics, Department of Public Health and Caring Sciences, \\ Uppsala University, Uppsala, Sweden
}

\section{Key Words}

Ethics - Genetic services market - Genetic testing ·

Psychosocial effects · Tragic choices

\begin{abstract}
Health-care systems as well as legislators and society seem largely unprepared to face and manage the massive production of genetic risk information. Ethics committees and professional bodies usually do not involve the individuals directly concerned in defining guidelines for genetic risk communication. Therefore, they do not always reflect people's needs and preferences. We argue in this article that we currently experience a cultural shift in medicine where individuals' concerns and preferences regarding genetic risk information are playing a more significant role than before, and that this should have some normative implications. We are going toward a situation where individual citizens are approached as consumers by personal genomics companies [Prainsack: Account Res 2011;18:132-147]. In clinical and research contexts, individuals are also increasingly informed about their own responsibilities for counterbalancing their genetic risk by making individual health care and lifestyle choices. In this situation, communication of genetic risk information may rather be regulated like traffic and markets in
\end{abstract}

which consumers' decision-making power has a fundamental role in the management and regulation of how a service should be provided, as well as in the creation of policy and legislation. We acknowledge that markets may be different depending on different genetic conditions. For example, genetic risk communication for rare diseases, where a close relationship with clinicians is of paramount significance, should be differently regulated than personal genetic profiles of complex diseases, where contributing risk factors related to lifestyle are modifiable by the individual.

(c) 2016 S. Karger AG, Basel

\section{Background}

For long, genetic testing has been provided by clinical geneticists in health-care settings. The genetic information has been given within a context of genetic counseling in order to give room to the individual to understand and relate to the information in the best possible way [1]. Genetic information is complex, and it may indirectly also concern an individual's family [2]. During recent years, we have seen an increasing number of companies offering genetic testing directly to consumers outside a healthcare setting [3]. This development has given rise to some

\section{KARGER}

E-Mail karger@karger.com

www.karger.com/phg
(C) 2016 S. Karger AG, Basel

$1662-4246 / 16 / 0195-0307 \$ 39.50 / 0$
Serena Oliveri

Interdisciplinary Research Center on Decision Making Processes IRIDe

Department of Oncology and Hematology, University of Milan

Via Festa del Perdono, 7, IT-20122 Milan (Italy)

E-Mail serena.oliveri@unimi.it 
concerns regarding both scientific and ethical/regulatory issues [4-6]. A report put together by professional geneticists, ethicists, and academic societies points at several important issues that need to be addressed in association with direct-to-consumer (DTC) genetic testing [7]. The report expresses special caution regarding testing for high penetrance, serious disorders, prenatal screening, nutrigenomic and pharmacogenetic testing. Of concern is also the transparent supply of accurate information, consideration of the implications for established health services, and clarification of consent procedures for any use of data collected within a DTC context for research purposes.

A key issue addressed in the report is the need for quality assurance of these types of genetic testing, and it is suggested that this should include the professional interpretation of the results of the testing [7]. We agree that this may be the right and most responsible way in many instances related to the communication of genetic information [8], and one of the authors of the present paper participated in an EASAC-FEAM working group and agreed with the conclusions of the abovementioned report [7]. However, with regard to the rapid development in genetic testing technologies, the increasing number of initiatives for provision of genetic testing outside the public health-care sectors, and the growing genetic literacy in society, we believe that the developing situation calls for a more nuanced approach both to clinical genetic testing and DTC genetic testing.

\section{Let the Individuals Decide}

A feature of policy proposals [7] on how to manage genetic risk information is that the individuals directly concerned are not capable of making decisions themselves on when to receive genetic risk information. An example is the current debate on how to report research results and incidental findings in association with wholegenome sequencing. An incidental finding is a finding concerning an individual research participant, which has a potential health or reproductive importance and which was discovered during the course of conducting research but is beyond the aims of the study [9]. The American College of Medical Genetics and Genomics recently proposed that a minimum list of conditions, genes, and variants should be routinely evaluated and reported to the ordering clinician without seeking preferences from the patient and family and without considering the limitations associated with the patient's age [10]. The European Society of Human Genetics takes a more conservative po- sition and urges caution over the use of new genetic sequencing techniques, including strongly opposing the kind of opportunistic screening proposed in the US [11]. Part of this kind of information may be trivial, but the major part is related to life and death or at least to significant elements of an individual's quality of life.

Concerning DTC genetic testing, the policy that this kind of life and death decision should not be left to the individuals directly concerned themselves may best be exemplified with the recent decision by the FDA to shut down 23andMe marketing in the US, since it may lead to serious consequences: '... if the BRCA-related risk assessment for breast or ovarian cancer reports a false positive, it could lead a patient to undergo prophylactic surgery, chemoprevention, intensive screening, or other morbidity-inducing actions, while a false negative could result in a failure to recognize an actual risk that may exist' (http:// www.fda.gov/ICECI/EnforcementActions/WarningLetters/2013/ucm376296.htm).

Clinical geneticists are almost unanimous in expressing their disapproval of offering genetic tests for nontreatable or nonpreventable conditions (such as Huntington's disease, dystonia, and muscular dystrophy) or for disorders with serious health consequences (such as familial adenomatous polyposis) without an established physician-patient relationship and without face-to-face medical supervision [12]. However, it should be observed that sometimes the complexity of clinical sequencing reports might be susceptible to misinterpretation also within health-care settings when judgments by nongeneticist physicians will lead to over- or underestimation of the disease risk associated with a given variant. Such results might lead physicians to order an expensive cascade of follow-up diagnostic tests, each with its own potential complications, risks to the patient, and economic costs [13]. The degree of physician preparedness is not better for genomic medicine than for other complex medical innovations such as myriad types of imaging, microscopic pathology assessment, or targeted therapies [14]. There is accordingly a need for a better genetic education in order to fill the existing gaps in nonspecialized physicians' knowledge. However, one should also observe that many patients would like a greater share in the process of making decisions about their health [15] and that, in the near future, practicing physicians are likely to more frequently encounter patients wishing to discuss genetic test results [8]. The shared decision-making assumption is that the individual is empowered by choice, and more empowered when more choices are offered [16]. Being allowed to make decisions will enable people to control their lives 
and act as autonomous individuals, being able to define their own needs, rather than their needs being defined for them by others $[17,18]$. For this reason, an alternative would be to let the individuals directly concerned decide for themselves when they want genetic risk information, when they want to take a genetic test, if they want to learn more about their genetic profiles, or when they want to try (experimental) treatments or participate in risky research, e.g. at what odds ratio of sensitivity and specificity they are willing to gamble.

Understanding the ways in which perceived risk and personal characteristics act as a motivator $[19,20]$ will help to tailor risk communication and genetic counseling appropriately [21], particularly for individuals whose preconceived perceptions of risk may be resistant to the standard education and counseling approaches undertaken in clinical genetics [22].

More broadly, to promote an active role of the general public we should invest in health literacy, shared decision-making and self-management when possible. Functional strategies may include written information and electronic information sources, virtual/computer-based supports and decision aids tailored on people's profiles and values, followed by training for health professionals in communication skills [23] and self-management education programs for patients/consumers.

\section{Choices in Genetics May Be Done Differently by Different Individuals}

A problem with making choices regarding genetics is that the outcomes may have a low predictability, and however much information is available, it cannot answer the crucial questions, e.g. will my baby be healthy, or will I develop the disease? For complex diseases (e.g. cardiovascular diseases, breast cancer, etc.), genetic risk information is in itself complex with many genetic factors building up the entire picture together with environmental and modifiable factors [24, 25].

Concerning chromosomal anomalies, e.g. trisomy 21 or Klinefelter syndrome, the accurate genetic information is directly available through a chromosome analysis. However, the implications for the individual may still be variable depending on family history, values, and preferences of the individuals and families concerned. Klinefelter syndrome is associated with obligate sterility and the need for social assistance in school, but on the whole, these boys do quite well. A couple who has been waiting for a child for a long time may accept this, but for anoth-

Market for Tragic Choices in Genetics er couple, who may have experienced previous pregnancies with more severe defects of a child, genetic information of this kind may be just what tips the balance (to decide for an interruption of pregnancy). Usually, women have to reconcile their concerns about risk with their moral stance on issues surrounding termination of pregnancy [26]. Accordingly, both regarding complex genetic information and information about monogenic disorders, the implications for those directly concerned are uncertain and variable due to different experiences as well as personal values and preferences. One does not know how different individuals will react to the provision of genetic information, but individuals want presumably to decide what to do based on what they can and want to live with. One needs, therefore, involve the individuals directly concerned.

\section{How to Deal with Tragic Choices}

Decisions on what kind of and how genetic information should be revealed to the patient or to directly concerned healthy individuals fall into what Calabresi and Bobbit [27] coined 'tragic choices'. Tragic choices are inevitable in any society where dignity and equal worth of the individual are important social values, while resources are scarce or, as is of relevance in the context discussed here, when setting limits for when to communicate genetic risk information for individuals to act on is vital. Decisions are tragic when tolerated despite the fact that they violate fundamental values that are accepted in a society. We confess to each individual's equal worth but allow and tolerate nevertheless that some individuals are treated differently or tolerate that they will suffer more, or even die. Tragic decisions are made at the level of allocation of scarce resources or at the level where conflicting values and interests are balanced. Another characteristic feature of tragic choices is that decisions are made in a manner or with a method that makes us tolerate the violation of the fundamental values that are accepted in a society.

An example related to risk assessment in association with medical research may illustrate this point. There is a tragic choice to be made here, since if the restrictions of imposing risks in medical research are too strict, the scientific evidence for medical treatment will be lacking, hence leading to an increased risk to patients. If there are no restrictions, research subjects may be exposed to significant risks of harm. Governments, regulatory authorities, ethics committees, etc. do not allocate deaths, but 
they assign statistical chances, risks of morbidity or death to be carried by different groups of individuals. They set a general framework of rules and guidelines and make decisions on that basis. However, although the ethics review boards operate on common first-order standards, there will always be differences in how individuals judge and in what they want to know about risks and how they act consequently. In a similar vein, there may be a difference in how professional geneticists and their organizations look upon the significance of genetic risk information for any specific individual and how this individual values knowing about the risk. In Calabresi and Bobbit's [27] terminology, the decisions by professional geneticists and their organizations on when, how, and what to tell about genetic risk information look like the decisions by a dispassionate jury when they make tragic choices, i.e. at the extreme decide on who will live and who will die. A jury is expected to take into account and act on the basis of the values and standards that are generally accepted in society, being dispassionate or ignorant as to what each individual may want. In the legal system, juries seem to work fine and have a reputation of being balanced, independent, and providing unbiased and socially accepted choices. However, regarding genetic information, the implications of any policy on when and how to communicate this information will be different for each individual depending on personal values, the situation in life, and individual preferences. For these reasons, we suggest that communication of genetic risk information is more similar to traffic regulation than to the decisions left to a dispassionate jury.

In Sweden, 450 individuals die each year in traffic accidents. Many of them would be saved through grade separation of roads and comprehensive and enforceable speed limits, but costs would be high and the restriction of individual liberties extensive. The actual 'decisions' are handed over to the road users, the bicyclists and the pedestrians. In traffic, the actual number of deaths is handed over to a market, and individuals are in principle at liberty in this market to minimize their risk by taking the train instead of using the car, buying a safer car, driving slower, etc.; 'thus we comfort ourselves in the belief that our society does not establish an acceptable number of auto deaths (or who will die), but that this figure results from thousands of independent, atomistic decisions' [27]. The actual number of deaths and determinations of who is going to die in traffic is handed over to a kind of market after the government has set the general legal framework and allocated money for the building of safe roads, etc. An individual who sets out on purpose to kill road users, bicyclists, or pedestrians will be punished as will drunk driving, but in ordinary traffic situations, a number of deaths are tolerated, even though confessions are made to 0 -visions. Individuals are in principle at liberty in this market model to minimize their risk by taking the train instead of using the car or buying a safer car and driving slower.

The market is sometimes also used for the allocation of risk exposure and scarce resources in health care, e.g. allowing individuals to expose themselves to the health risks associated with smoking, drinking, rock-climbing, and hockey playing or to engage in prevention activities, such as eating a better diet, stop smoking, slowing down in order to minimize stress, etc. In a similar vein, decisions on what kind of genetic information should be given, as well as when and how, may be referred to the market of directly concerned individuals, in this case those wanting to explore their genetic profiles, with e.g. the purpose of adjusting their lifestyles accordingly. Such a market may be regulated in a similar vein as traffic and as markets involving a choice with open and accredited information, quality checks, and competition laws (fig. 1).

Traffic and genetic risk information are different in many respects but share some interesting features. The traffic system enables choices to be made according to individual needs and preferences, but no choices are absolutely safe. Genetic risk information implies the risk of disease or death even if some risks are modifiable, but also here, individuals have different needs and preferences on when to know and what to do. Traffic regulation is addressed to the general public, and the state authority is very strong in setting up binding rules for drivers, bicyclists, etc. The regulation of genetic information communication has so far been addressed to professional experts and their institutions. However, we currently experience a cultural shift in medicine where concerns and preferences of individual members of the general public regarding genetic risk information are playing a more significant role than before. We are going from a culture where communication of genetic information was the sole concern of professional geneticists and doctors to a situation when individual citizens to an increasing extent are approached as consumers by personal genomics companies [28]. In clinical and research contexts, individuals are also increasingly informed about their own responsibilities for counterbalancing their genetic risk by making individual health-care and lifestyle choices, based on the information they can acquire both by their doctors and through all kinds of openly available information sources $[29,30]$. Figuratively speaking, regarding communica- 


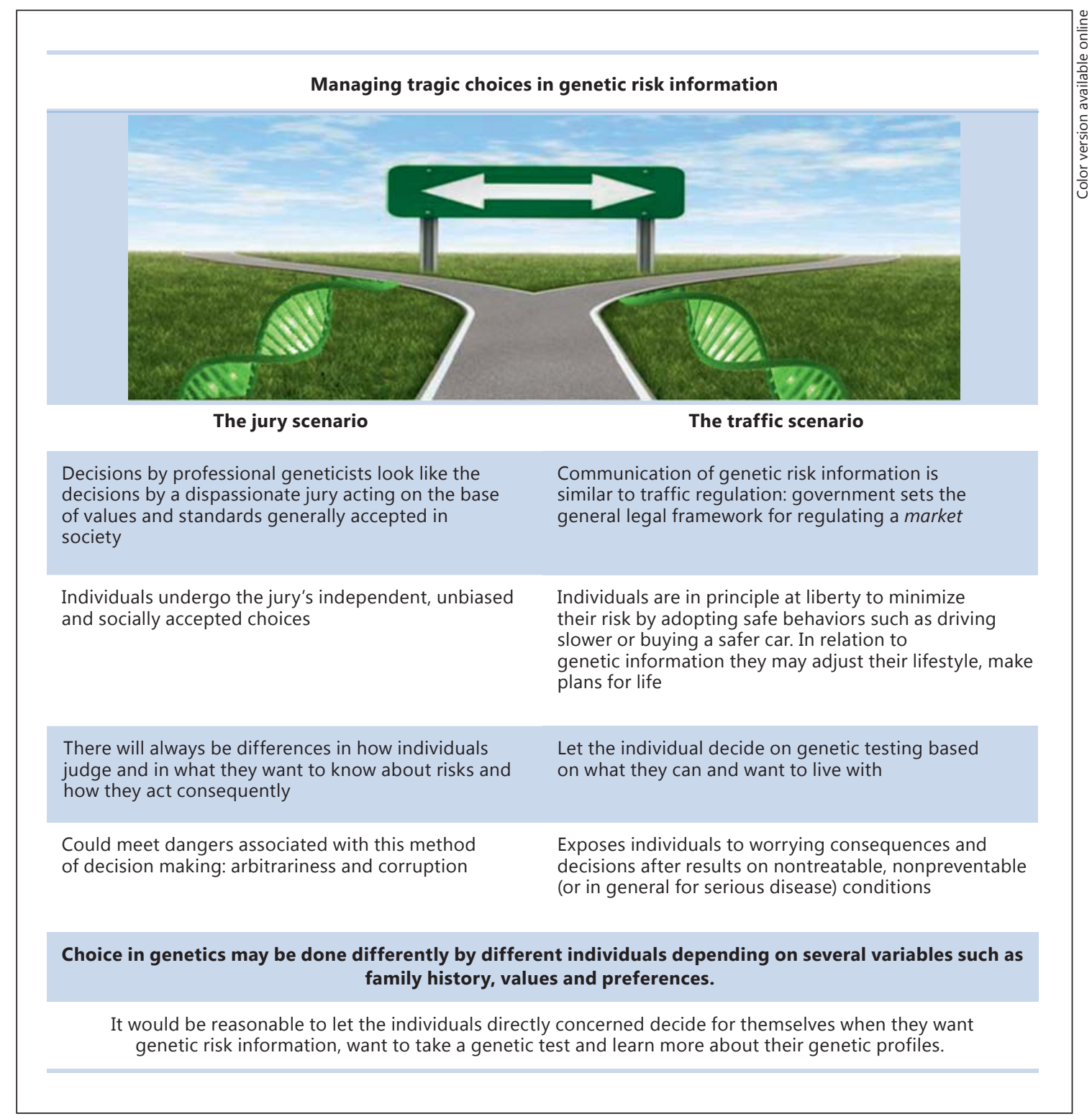

Fig. 1. Managing tragic choices in genetic risk information. Two possible scenarios regarding how regulatory bodies, ethics committees, etc. may approach regulation in genetic risk information.

tion of genetic risk information we are moving from a situation with only public transportation available to a modern multidimensional traffic system that better fits different needs and preferences. This should then be reflected in regulation and policy making, and we suggest that there should be a role for state authority here as well as some regulations, e.g. regarding the accuracy of the information provided and surveillance by state authorities of the quality of services provided.

Market for Tragic Choices in Genetics

\section{Markets May Be Different and May Not Suit All Genetic Conditions}

There are also genetic conditions that may not be suitable for a market model and where a close relationship with the clinic and the expertise of geneticists, doctors, and counsellors is of paramount significance. This is the case for several dysmorphic syndromes, where a distinctive genetic cause may not be available but judgements 
based on long clinical experience and consultations with several professionals are necessary [31].

A potential free market may instead be un- or underdiagnosed patients with rare diseases, where the clinic fails to provide any answers or to put in sufficient efforts according to these families' expectations and sufferings. A sign of the unmet need for genotyping and advice for this group of patients is the response to the recently launched National Institutes of Health Undiagnosed Diseases Program where 800 patients travelled across the country to the clinical center of the program for weeklong consultations and testing [32]. For a family with a child that has an obvious medical disability but no clear diagnosis, the situation may be very frustrating and may require the consultation of several doctors in seeking the cause of the child's illness. The gravity of the problem is evident from a study of the diagnostic delay in patients with hereditary hemorrhagic telangiectasia. The mean clinical onset of the disease occurred at 14.1 years, while the age of first referral to a doctor and the age of a definite diagnosis were 29.2 and 40.1 years, respectively [33]. The diagnostic delay was mainly due to a lack of knowledge among the health-care professionals, insufficient disease awareness among the families of the patients, and a lack of diagnostic tools. With the recent availability of nextgeneration sequencing, there is a solution regarding the last factor, and there are many laboratories that can do the testing. It has only to be made available and the market has to be appropriately organized in order for these patients and their families to get test results that they in turn may bring back to an appropriate clinic.

\section{Acknowledgments}

This work was supported by a grant for the project 'Mind the Risk' from The Swedish Foundation for Humanities and Social Sciences, Grant No. M13-0260:1, which had no influence on the content of this paper.

\section{Disclosure Statement}

The authors declare that they have no competing interests.

\section{References}

$\checkmark 1$ Andrews LB, Fullarton JE, Holtzman NA, Motulsky AG (eds): Assessing Genetic Risks: Implications for Health and Social Policy, Vol 1. Washington, DC, National Academies Press, 1994

-2 Gilbar R: Communicating genetic information in the family: the familial relationship as the forgotten factor. J Med Ethics 2007;33: 390-393.

3 Su P: Direct-to-consumer genetic testing: a comprehensive view. Yale J Biol Med 2013;86: 359.

4 Hogarth S, Javitt G, Melzer D: The current landscape for direct-to-consumer genetic testing: legal, ethical, and policy issues. Annu Rev Genomics Hum Genet 2008;9:161-182.

5 Hansson MG: Taking the patient's side: the ethics of pharmacogenetics. Per Med 2010;7: $75-85$.

6 6 Caulfield T, McGuire AL: Direct-to-consumer genetic testing: perceptions, problems, and policy responses. Annu Rev Med 2012;63:2333.

7 Fears R, ter Meulen V; EASAC-FEAM Working Group: The perspective from EASAC and FEAM on direct-to-consumer genetic testing for health-related purposes. Eur J Human Genet 2013;21:703-707.

-8 Sharp RR, Goldlust ME, Eng C: Addressing gaps in physician education using personal genomic testing. Genet Med 2011;13:750751
9 Wolf SM, Lawrenz FP, Nelson CA, Kahn JP, Cho MK, Clayton EW, Illes J: Managing incidental findings in human subjects research: analysis and recommendations. J Law Med Ethics 2008;36:219-248.

10 Green RC, Berg JS, Grody WW, Kalia SS, Korf BR, Martin CL, Rehm HL: ACMG recommendations for reporting of incidental findings in clinical exome and genome sequencing. Genet Med 2013;15:565-574.

11 van El CG, Dondorp WJ, De Wert GMWR, Cornel MC: ESHG calls for prudent use of WGS-based testing. Science 2013;341:958959.

12 Howard HC, Borry P: Survey of European clinical geneticists on awareness, experiences and attitudes towards direct-to-consumer genetic testing. Genome Med 2013;5:45.

13 McGuire AL, Burke, W: An unwelcome side effect of direct-to-consumer personal genome testing: raiding the medical commons. JAMA 2008;300:2669-2671.

14 Vassy JL, Korf BR, Green RC: How to know when physicians are ready for genomic medicine. Sci Transl Med 2015;7:287fs19.

15 Grol R, Wensing M, Mainz J, Jung HP, Ferreira $\mathrm{P}$, Hearnshaw $\mathrm{H}$, et al; European Task Force on Patient Evaluations of General Practice Care (EUROPEP): Patients in Europe evaluate general practice care: an international comparison. Br J Gen Pract 2000;50:882887.
16 Levit L, Balogh E, Nass S, Ganz PA: Patientcentered communication and shared decision making; in: Delivering High-Quality Cancer Care: Charting a New Course for a System in Crisis. Washington, DC, Institute of Medicine, 2013, pp 91-125.

17 Ahlquist L: Practising Empowerment. Empowerment in Action. Edinburgh, Age Concern Scotland, 1997.

18 Hansson MG: The Private Sphere: An Emotional Territory and Its Agent. Philosophical Studies in Contemporary Culture, Vol 15. Springer Netherlands, Springer Science \& Business Media, 2007.

19 Oliveri S, Renzi C, Pravettoni G: Toward an in-depth profiling of DTC users. Clin Genet 2015;88:505-506.

-20 Katapodi MC, Lee KA, Facione NC, Dodd MJ Predictors of perceived breast cancer risk and the relation between perceived risk and breast cancer screening: a meta-analytic review. Prev Med 2004;38:388-402.

21 Bottorff JL, Ratner PA, Johnson JL, Lovato CY, Joab SA: Communicating cancer risk information: the challenges of uncertainty. Patient Educ Couns 1998;33:67-81.

22 Croyle RT, Lerman C: Risk communication in genetic testing for cancer susceptibility. J Natl Cancer Inst Monogr 1999;25:59-66. 
23 Fioretti C, Smorti A: Improving doctor-patient communication through an autobiographical narrative theory. Commun Med 2014;11:275-284

24 Yusuf S, Hawken S, Ônpuu S, Dans T, Avezum A, Lanas F; INTERHEART Study Investigators: Effect of potentially modifiable risk factors associated with myocardial infarction in 52 countries (the INTERHEART study): case-control study. Lancet 2004;364:937-952.

25 Institute of Medicine: Breast Cancer and the Environment: A Life Course Approach. Washington, DC, National Academies Press, 2012, pp 52-53.

26 Sivell S, Elwyn G, Gaff CL, Clarke AJ, Iredale $\mathrm{R}$, Shaw C, Edwards A: How risk is perceived, constructed and interpreted by clients in clinical genetics, and the effects on decision making: systematic review. J Genet Couns 2008; 17:30-63.
27 Calabresi G, Bobbitt P: Tragic Choices. New York, WW Norton \& Company, 1978.

28 Prainsack B: Voting with their mice: personal genome testing and the 'participatory turn' in disease research. Account Res 2011;18:132147.

29 McBride CM, Koehly LM, Sanderson SC, Kaphingst KA: The behavioral response to personalized genetic information: will genetic risk profiles motivate individuals and families to choose more healthful behaviors. Annu Rev Public Health 2010;31:89-103.
30 Mendick N, Young B, Holcombe C, Salmon $\mathrm{P}$ : The ethics of responsibility and ownership in decision-making about treatment for breast cancer: triangulation of consultation with patient and surgeon perspectives. Soc Sci Med 2010;70:1904-1911.

31 Featherstone K, Gregory M, Atkinson PA: The moral and sentimental work of the clinic: the case of genetic syndromes; in Atkinson PA, Glasner PE, Greenslade HT (eds): New Genetics, New Identities. London, Routledge, 2006, pp 101-119.

32 Tifft CJ, Adams DR: The National Institutes of Health undiagnosed diseases program. Curr Opin Pediatr 2014;26:626-633.

-33 Pierucci P, Lenato GM, Suppressa P, Lastella $\mathrm{P}$, Triggiani V, Valerio R, Sabbà C: A long diagnostic delay in patients with hereditary haemorrhagic telangiectasia: a questionnairebased retrospective study. Orphanet J Rare Dis 2012;7:33. 